\title{
INDUÇÃO DA ENZIMA PIROCATECASE POR Acinetobacter baumanii ENVOLVIDA NA BIODEGRADAÇÃO DO HERBICIDA DIURON
}

\author{
SHIRLEI SCRAMIN * \\ ANAMARIA FERREIRA MAYER DENTZIEN ** \\ ITAMAR SOARES DE MELO ***
}

\begin{abstract}
Uma linhagem de Acinetobacter baumanii, isolada da rizosfera de cana-de-açúcar, cultivada em solos tratados com Diuron foi incubadada em diferentes substratos para verificar a presença de catecol 1,2dioxigenase (pirocatecase). Diferentes indutores foram adicionados ao meio de cultura (glicose, benzoato de sódio, Diuron, dicloroanilina, benzoato de sódio + glicose, benzoato de sódio + dicloroanilina, Diuron + glicose). As células bacterianas, obtidas pelo processo fermentativo, foram coletadas após centrifugação e rompidas por sonicação para extração da enzima intracelular. A linhagem apresentou alta atividade enzimática quando benzoato de sódio ou benzoato de sódio + glicose ou benzoato de sódio + dicloroanilina foram adicionados ao meio de cultura. A atividade enzimática acompanhou a produção de biomasa. No estudo da cinética de crescimento, usando Diuron como fonte de carbono e em três diferentes $\mathrm{pH}$, essa linhagem apresentou melhor resultado quando cultivada em $\mathrm{pH} 6,8$. Verificou-se pela avaliação da capacidade de A. baumanii transformar o Diuron, que o metabólito 3,4-dicloroanilina (3,4-DCA) não foi produzido.
\end{abstract}

PALAVRAS-CHAVE: Acinetobacter Baumanii; FERMENTAÇÃO LÍQUIDA; ATIVIDADE ENZIMÁTICA; DIURON; 3,4-DCA.

* Farmacêutica-Bioquímica, Doutorado em Química Orgânica, Embrapa Meio Ambiente, Jaguariúna, SP.

** Bióloga, Mestrado em Ciências Biológica/Botânica, Embrapa Meio Ambiente, Jaguariúna, SP.

*** Engenheiro Agrônomo, Doutorado em Agronomia, Embrapa Meio Ambiente, Jaguariúna - SP (e-mail: Itamar@cnpma.embrapa.br). 


\section{INTRODUÇÃO}

A biodegradação de compostos orgânicos sintéticos determina o destino e o "comportamento" desses poluentes no ambiente. O entendimento das reações bioquímicas envolvidas no metabolismo de tais compostos constitui a base para identificar a duração de sua persistência na natureza.

O herbicida Diuron do grupo das feniluréias, aplicado principalmente em cana-de-açúcar, tem 3,4-dicloroanilina como um dos principais produtos do seu metabolismo. Trata-se de metabólito persistente e recalcitrante, presente no solo e em ambientes aquáticos (GEISSBUHLER, MARTIN e VOSS, 1975; ROCHKIND-DUBINSKY, SAYLER e BLACKBURN, 1987). As cloroanilinas são insumos importantes na síntese de herbicidas (espalhadas no ambiente de forma dispersa), representando problema ambiental pela característica xenobiótica dos compostos aromáticos clorados. Muitos desses compostos apresentam toxicidade elevada, alguns sendo carcinogênicos (LYONS et al., 1985; HEIN et al., 1991). No entanto, certas bactérias são capazes de transformar essas moléculas, a exemplo de Pseudomonas e Acinetobacter dentre outras. O gênero Acinetobacter tem sido envolvido na biorremediação de solos contaminados com lignina, fenol, PCB e outros cloroaromáticos (STRAND, 2003; VASUDEVAN e MAHADEVAN, 1992).

Foi demonstrado que o catecol constitui-se em um intermediário na degradação de muitos compostos aromáticos clorados e seu metabolismo pode ocorrer tanto por clivagem entre os grupos hidroxila (clivagem orto ou intradiol), como por clivagem adjacente a um dos grupos hidroxila (clivagem meta ou extradiol (SCHLÖMANN, 1994; WILLIAMS e SAYERS, 1994). Como cada uma dessas reações origina vias metabólicas diferentes, a presença das enzimas envolvidas nesses processos tem sido usada como indicador de degradação (GIBSON, 1971). Com relação à clivagem orto, algumas linhagens bacterianas que metabolizam as cloroanilinas produzem altos níveis da enzima pirocatecase II, que atua na via metabólica da degradação das cloroanilinas (ROCHKIND-DUBINSKY, SAYLER e BLACKBURN, 1987; HINTEREGGER e LOIDL, 1992). Por outro lado, a presença da enzima pirocatecase I está envolvida na degradação da anilina evidenciando a existência de duas enzimas isofuncionais que atuam na clivagem orto desses compostos aromáticos (HINTEREGGER e LOIDL, 1992).

Estudos mostraram que determinada cepa de Pseudomonas metaboliza o fenol seguindo a via da clivagem meta e o benzoato pela via da clivagem orto, independente do intermediário comum (o catecol). O fenol é o indutor da via meta, promovendo a produção da enzima metapirocatecase. $\mathrm{Na}$ ausência desse substrato indutor, o metabolismo do catecol não ocorre e seu acúmulo dispara o mecanismo de feedback, que promove a produção da pirocatecase, seguindo assim a via orto (MURRAY e WILLIAMS, 1974). Essas observações podem ser válidas para outros organismos degradadores de compostos aromáticos e a presença da enzima metapirocatecase pode estar associada ao substrato utilizado para seu crescimento.

O presente trabalho visou avaliar e quantificar a produção da enzima intracelular pirocatecase de Acintobacter baumanii, envolvida na degradação de cloroanilinas, utilizando diferentes substratos como indutores enzimáticos. Foram realizados estudos metodológicos sobre o rompimento celular para extração da enzima intracelular, além da avaliação da cinética de crescimento dessa linhagem e a sua capacidade de transformar o herbicida Diuron.

\section{MATERIAL E MÉTODOS}

Linhagem de Acinetobacter baumanii, D12-18, isolada de solos rizosféricos de cana-de-açúcar com histórico de aplicação de Diuron (ROQUE, 2000) e envolvida na biodegradação desse herbicida.

\subsection{PRODUÇÃO DE BIOMASSA}

A biomassa foi obtida pelo processo de fermentação utilizando-se o protocolo estabelecido por 
NAKAZAWA e NAKAZAWA (1970), a partir de pré-cultivo de $A$. baumanii feito em meio sólido LB ágar. Iniciou-se o processo de pré-fermentação após $48 \mathrm{~h}$ de cultivo. Para a pré-fermentação transferiuse pequena quantidade de células para $25 \mathrm{~mL}$ de meio líquido, contendo os indutores (benzoato de sódio $-0,1 \%$ ou Diuron $-20 \mathrm{mg} / \mathrm{L}$ ou glicose $-0,1 \%$ ou dicloroanilina $-4 \mathrm{mg} / \mathrm{L}$ ou BS+GLIC ou $\mathrm{BS}+\mathrm{DCA}$ ou DIU+GLIC) e extrato de levedura $\left(0,05 \% ;\left(\mathrm{NH}_{4}\right)_{2} \mathrm{HPO}_{4}-0,30 \% ; \mathrm{KH}_{2} \mathrm{PO}_{4}-0,12 \% ; \mathrm{NaCl}\right.$ $0,17 \% ; \mathrm{FeSO}_{4} \cdot 7 \mathrm{H}_{2} \mathrm{O}-0,01 \% ; \mathrm{MgSO}_{4} \cdot 7 \mathrm{H} 2 \mathrm{O}-0,02 \% ; \mathrm{H}_{2} \mathrm{O}$ destilada - $1000 \mathrm{~mL}$ ). O meio foi mantido a $30^{\circ} \mathrm{C}$ sob agitação a $180 \mathrm{rpm}$, por 8 horas. Após esse período, efetuou-se novo repique, usando a proporção de $5 \%$ de inóculo (obtido da 1a pré-fermentação) para cada frasco de novo meio de cultura, mantendo-se as mesmas condições da cultura por mais 16 horas. A fermentação (propriamente dita) começou ao final dessa segunda repicagem, quando o caldo de cultura foi introduzido no meio esterilizado já no fermentador. Usou-se a proporção de $5 \%$ de inóculo em relação ao volume de meio conforme a capacidade do fermentador e as seguintes condições: temperatura de $30^{\circ} \mathrm{C}$, agitação a $180 \mathrm{rpm}$ e aeração a $0,4 \mathrm{vvm}$ por $18 \mathrm{~h}$. Decorrido o tempo, a fermentação foi interrompida e o caldo centrifugado a $4^{\circ} \mathrm{C}$ para retirada das bactérias. Essas foram lavadas com $\mathrm{KCl} 0,85 \%$, centrifugadas em centrífuga refrigerada Sorvall por $30 \mathrm{~min}$ a $10.000 \mathrm{~g}, 4^{\circ} \mathrm{C}$, sendo as células armazenadas em freezer.

\subsection{SONICAÇÃO}

Efetuou-se a extração da enzima intracelular pelo rompimento das células, utilizando-se sonicador (homogeneizador ultra-sônico) da Cole-Parmer. As células (10 g) foram ressuspendidas em béquer, com $40 \mathrm{~mL}$ de solução tampão TRIS $0,05 \mathrm{M}, \mathrm{pH} 9,0$. O béquer com a solução foi mantido em recipiente de isopor contendo gelo, álcool e sal para manter resfriamento em torno de $3^{\circ} \mathrm{C}$ a $4{ }^{\circ} \mathrm{C}$. A sonicação ocorreu nas seguintes condições: potência de 120 watts, amplitude de $50 \%$, tempo de 3 minutos (tempo efetivo), pulsos de 1 segundo, com intervalos de 2 segundos, sendo que a temperatura não ultrapassou $12^{\circ} \mathrm{C}$ (MAcMULLAN e QUINN, 1992). Após centrifugação por 10 minutos a $15.000 \mathrm{~g} / 4^{\circ} \mathrm{C}$, o sobrenadante contendo a enzima intracelular foi recolhido e armazenado em freezer.

\subsection{AVALIAÇÃO DA ATIVIDADE DA PIROCATECASE}

Usou-se o ensaio de NAKASAWA e NAKASAWA (1970) para avaliar a atividade da pirocatecase, baseado na formação do ácido cis-mucônico a partir da oxidação do catecol. Foram colocados em cubeta de vidro de $3 \mathrm{~mL}, 300 \mu \mathrm{L}$ da solução tampão fosfato de potássio $0,1 \mathrm{M} \mathrm{pH} 7,5,100 \mu \mathrm{L}$ de catecol $0,01 \mathrm{M}, 100 \mu \mathrm{L}$ da solução enzimática e $2,5 \mathrm{~mL}$ de água destilada. Mediu-se a absorbância da mistura em Espectrofotômetro, Perkin-Elmer, modelo Lambda 20, a $375 \mathrm{~nm}$, a cada 30 segundos, por 3 minutos, a $24^{\circ} \mathrm{C}$. Obteve-se o resultado em unidades por litro (U.L-1 $)$, sendo utilizado para o cálculo final o coeficiente de extinção molar de 16.000 para essas condições. Uma unidade de atividade corresponde à quantidade de enzima que oxida um micromol de catecol por minuto a $24^{\circ} \mathrm{C}$.

\subsection{ESTUDO DA CINÉTICA DE CRESCIMENTO DE Acinetobacter Baumanii}

A cinética de crescimento de $A$. baumanii, cultivada em meio de NAKASAWA com 20 mg.L-1 de Diuron em pH diferentes ( $\mathrm{pH} 4,8 ; \mathrm{pH} 5,5 ; \mathrm{pH} \mathrm{6,8)}$ ), foi avaliada em intervalos de quatro horas, em Espectrofotômetro (Perkin-Elmer, modelo Lambda 20), a $580 \mathrm{~nm}$. As amostras utilizadas nas leituras foram retiradas dos minifermentadadores, marca NEWBRUNSWICK, modelo MULTIGEN, com capacidade de 1 litro.

\subsection{AVALIAÇÃO DA BIODEGRADABILIDADE DE DIURON EM PRESENÇA DE Acinetobacter Baumanii}

A linhagem de A. baumanii (D12-18) foi cultivada em meio J.E. (JONES e EDINGTON, 1968) 
suplementado com Diuron nas concentrações de $20 \mathrm{~g} \cdot \mu \mathrm{L}^{-1}$ e $50 \mu \mathrm{g} \cdot \mathrm{mL}^{-1}$. O meio foi avaliado quanto à presença de metabólitos, principalmente, 3,4-dicloroanilina (DCA), utilizada como padrão de transformação do Diuron.

As culturas foram incubadas por 48 horas sob agitação $\left(180 \mathrm{rpm}, 28^{\circ} \mathrm{C}\right)$. Após esse período avaliou-se a transformação do herbicida em cromatografia de camada delgada (CCD). Para isso, extratos concentrados do meio de cultura com a bactéria foram aplicados em placa de sílica gel/UV $\mathrm{UV}_{254}$ (Whatman) na quantidade de $10 \mu \mathrm{L}$, tendo sido aplicado também o padrão analítico de DCA como referência.

Usou-se diclorometano/metanol (95:5) como eluente para o desenvolvimento do cromatograma, sendo as manchas identificadas sob luz ultravioleta. O cálculo do índice de retenção (Rf) foi realizado conforme a equação 1:

$$
\mathrm{Rf}=\frac{\text { dist ncia percorrida pela subst ncia teste }}{\text { dist ncia do eluente }}
$$

\section{RESULTADOS E DISCUSSÃO}

Os resultados obtidos (Tabela 1) demonstraram que (tanto para a produção de biomassa como para a expressão da atividade enzimática) a suplementação com os indutores benzoato de sódio ou benzoato de sódio mais glicose ou benzoato de sódio mais dicloroanilina contribuiu para maior indução de pirocatecase pela bactéria. É possível que essa linhagem tenha se adaptado melhor aos meios de cultura que continham um desses indutores como única fonte de carbono, demonstrando o caráter indutível dos genes envolvidos no processo. Essa linhagem, além de transformar o herbicida Diuron, foi capaz de mineralizar o ${ }^{14} \mathrm{C}$ - Diuron em pequenas taxas (ROQUE, 2000). DELLAMATRICE et al. (2001) também isolaram linhagem de $A$. jonsonii capaz de mineralizar cerca de $3 \%$ de Diuron. Supõese, então, que esse gênero possa conter genes envolvidos na adaptação e mineralização de moléculas do grupo das anilinas. Também pode-se considerar o fato de que essas linhagens bacterianas tenham sido isoladas em áreas com forte pressão seletiva, já que o Diuron, o Linuron e o Monuron representam mais de $50 \%$ dos herbicidas aplicados em cana-de-açúcar.

Para a obtenção dos resultados de avaliação da atividade enzimática foi necessário adaptar a metodologia de extração da enzima intracelular, que tem sido utilizada em trabalhos realizados com outros gêneros bacterianos (MAcMULLAN e QUINN, 1992; MURATA et al., 1988). Esse procedimento mostrou-se extremamente eficaz para a extração do conteúdo intracelular e apresentou maior atividade enzimática quando comparado com ensaios prévios utilizando "bead beater" na ruptura das células bacterianas. Para a otimização do processo de extração, que correspondeu ao aumento da atividade enzimática, foram realizados ensaios preliminares envolvendo a sonicação das células em diferentes condições. Variou-se o tempo de sonicação (minutos) e a temperatura $\left(4^{\circ} \mathrm{C}\right.$ a $\left.15^{\circ} \mathrm{C}\right)$, sendo as condições definidas em material e métodos as que mostraram os melhores resultados na extração da pirocatecase.

A biomassa obtida nas fermentações apresentou diferentes resultados, embora os mesmos procedimentos tenham sido adotados para todos os ensaios. O mesmo ocorreu quanto à atividade enzimática expressa por $A$. baumanii, quando cultivada em presença dos diferentes indutores. $\mathrm{Na}$ avaliação dessa linhagem quanto à capacidade de transformar o herbicida Diuron, utilizando CCD para verificar a presença de metabólitos, observou-se que a bactéria apresentou valor de Rf igual a 0,12 (Tabela 2). Como não foi aplicado o herbicida Diuron na placa cromatográfica não foi possível avaliar qual o composto presente na amostra. No entanto, confirmou-se que o metabólito 3,4-dicloroanilina não foi produzido.

O estudo da cinética de crescimento da bactéria mostrou melhor resultado quando a linhagem de $A$. baumanii foi cultivada em pH 6,8 (Figura 1). Esse resultado evidencia melhor adaptação da bactéria às condições do meio de cultura em $\mathrm{pH} 6,8$, que proporcionou maior crescimento celular do que os apresentados nos outros valores de $\mathrm{pH}$. 
TABELA 1 - BIOMASSA DE Acinetobacter Baumanii EM DIFERENTES INDUTORES E AVALIAÇÃO DA ATIVIDADE ENZIMÁTICA DA PIROCATECASE

\begin{tabular}{ccc}
\hline Indutores & $\begin{array}{c}\text { Biomassa } \\
\left(\mathrm{mg} \mathrm{I}^{-1}\right)\end{array}$ & $\begin{array}{c}\text { Atividade EnzimAtica* } \\
\left(\mathrm{U}^{*} \mathrm{~L}^{-1}\right)\end{array}$ \\
\hline BS & 3.9004 & 0.234 \\
BS + DCA & 5.7184 & 0.206 \\
BS + GLI & 4.6863 & 0.800 \\
D CA & 0.8874 & 0.017 \\
D IU & 1.1218 & 0.030 \\
DIU + GLI & 1.4819 & 0.012 \\
GLI & 1.9415 & 0.015 \\
\hline
\end{tabular}

* Média de três repetições.

BS = Benzoato de sódio; $B S+D C A=$ Benzoato de sódio + Dicloroanilina; $B S+$ GLI = Benzoato de sódio + Glicose; DCA = Dicloroanilina; DIU = Diuron; DIU + Gli = Diuron + Glicose; Gli = Glicose.

\section{TABELA 2 - VALORES DE RF PARA O MEIO DE CULTURA SUPLEMENTADO COM DIURON DILUÍDO EM ÁGUA E INOCULADO COM A LINHAGEM D12-18 APÓS 48 HORAS DE INCUBAÇÃO E PARA A 3,4-DICLOROANILINA}

\begin{tabular}{ccc}
\hline LINHAGEM & \multicolumn{2}{c}{ DIURON } \\
\cline { 2 - 3 } & $20 \mu \mathrm{g} \mathrm{mL}^{-1}$ & $50 \mu \mathrm{g} \mathrm{\textrm {LL } ^ { - 1 }}$ \\
\hline DCA & 0,42 & 0,42 \\
D12-18 & 0,12 & 0,12
\end{tabular}

$D C A=$ dicloroanilina

FIGURA 1 - CINÉTICA DE CRESCIMENTO DE Acinetobacter Baumanii EM MEIO SUPLEMENTADO COM 20 m.L-1 DE DIURON, EM 3 DIFERENTES pH, AVALIADA PELA LEITURA DE ABSORBÂNCIA $(580 \mathrm{~nm})$

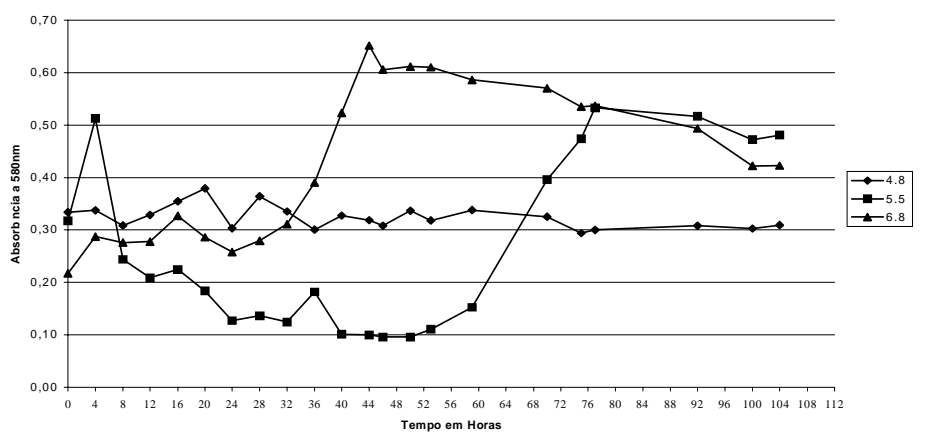

4 CONCLUSÃO

A expressão da atividade enzimática é indutiva, demonstrando que os suplementos benzoato de sódio, benzoato mais glicose e benzoato de sódio mais dicloroanilina levam a linhagem de $A$. baumanii a expressar essa atividade em maior proporção.

Maior produção de biomassa também ocorreu quando da adição dos suplementos benzoato de sódio, benzoato mais glicose e benzoato de sódio mais dicloroanilina.

A sonicação mostrou-se eficiente para o rompimento das células bacterianas, resultando em maior liberação da enzima intracelular.

O estudo da cinética de crescimento da bactéria mostrou melhor resultado quando a linhagem de $A$. baumanii foi cultivada em $\mathrm{pH} 6,8$. 


\begin{abstract}
PYROCATECHASE INDUCED BY Acinetobacter baumanii INVOLVED IN THE BIODEGRADATION OF THE HERBICIDE DIURON

An Acinetobacter baumanii strain, isolated from Diuron treated sugarcane rhizosphere, was grown in different substrates in order to determine the catechol 1,2-dioxygenase (pyrocatechase) presence. Different inducers were added to the culture media (glucose, sodium benzoate, Diuron, dichloroaniline, sodium benzoate plus glucose, sodium benzoate plus dichloroaniline, and Diuron plus glucose). The bacterial cells were harvested by centrifugation and disrupted by sonication for intracellular enzyme extraction. The strain showed high activity of pyrocatechase when sodium benzoate or sodium benzoate plus glucose or sodium benzoate plus dicloroaniline were added to the culture media. The enzymatic activity followed the biomass production. According to the growing kinetics study using Diuron as a carbon source, and with three different $\mathrm{pH}$, this strain showed the best result when growed at $\mathrm{pH}$ 6.8. Estimating the $A$. baumanii capacity of transforming Diuron, it was observed that the 3,4-dichloroaniline (3,4-DCA) metabolite was not produced.

KEY-WORDS: Acinetobacter Baumanii; LIQUID FERMENTATION; ENZIMATIC ACTIVITY; 3,4-DCA;DIURON.
\end{abstract}

\title{
REFERÊNCIAS
}

1 DELLAMATRICE, P. M.; MONTEIRO, R. T. R.; ROQUE, M. R. A.; MELO, I. S. Degradação de ${ }^{14}$ C-Diuron por Acinetobacter e pela microbiota do solo. In: MELO, I. S.; SILVA, C. M. M. S.; SCRAMIN, S.; SPESSOTO, A. (Ed.). Biodegradação. Jaguariúna: Embrapa Meio Ambiente, 2001. p. 349-352.

2 GEISSBUHLER, H.; MARTIN, H.; VOSS, G. Phenylureas. In: KEARNEY, P. C.; KAUFMAN, D. D. (Ed.). Herbicides: chemistry, degradation and mode of action. $2^{\text {nd }}$ ed. New York: Marcel Dekker, 1975. v. 1, p. 216-218.

3 GIBSON, D. T. Assay of enzymes of aromatic metabolism. In: NORRIS, J. R.; RIBBONS, D. W. Methods in microbiology. London: Academic Press, 1971. v. 6A, p. 463-478.

4 HEIN, D. W.; RUSTAN, T. D.; BUCHER, K. D.; MILLER, L. S. Polymorphic and monomorphic expression of arylamine carcinogen $\mathrm{N}$-acetyltransferase isozymes in tumor target organ cytosols of Syrian hamsters congenic at the polymorphic acetyltransferase locus. Journal of Pharmacology and Experimental Therapeutics, Baltimore, v. 259, n. 2, p. 699-704, 1991

5 HINTEREGGER, C.; LOIDL, M. Characterization of isofunctional ring-cleaving enzymes in aniline and 3-chloroaniline degradation by Pseudomonas acidovorans CA28. FEMS Microbiology Letters, Amsterdam, v. 97, n. 2, p. 261-266, 1992

6 JONES, J. G.; EDINGTON, M. A. An ecology survey of hydrocarbon-oxidizing microorganisms. Journal of General Microbiology, London, v. 37, p. 381-390, 1968

7 LYONS, C. C.; KATZ, S. E.; BARTHA, R. Persistence and mutagenic potential of herbicide-derived aniline residues in pond water. Bulletin of Environmental Contamination and Toxicology, New York, v. 35, n. 5, p. 696-703, 1985.

8 McMULLAN, G.; QUINN, J. P. Detection of a novel carbon-phosphorus bond cleavage activity in cell-free extracts of an environmental Pseudomonas fluorescens isolates. Biochemical and Biophysical Research Comunications, New York, v. 184, n. 2, p. 1022-1027, 1992

9 MURATA, K.; HIGAKI, N.; KIMURA, A. A microbial carbon-phosphorus bond cleavage enzyme requires two protein components for activity. Biochemical and Biophysical Research Communications, New York, v. 157, n. 1, p. 190-195, 1988.

10 MURRAY, K.; WILLIAMS, P. A. Role of cathecol and the methylcatechols as inducers of aromatic metabolism in Pseudomonas putida. Journal of Bacteriology, Washington, v. 117, n. 3, p. 1153-1157, 1974.

11 NAKAZAWA, T.; NAKAZAWA, A. Pyrocatechase (Pseudomonas). In: TABOR, H.; TABOR, C. W. (Ed.). Methods in enzymology. New York: Academic Press, 1970. v. 17A, p. 518-522.

12 ROCHKIND-DUBINSKY, M. L.; SAYLER, M. L.; BLACKBURN, J. W. Microbial decomposition of chlorinated aromatic compounds. New York: Marcel Dekker, 1987. (Microbiology Series, 18)

13 ROQUE, M. R. A. Isolamento, caracterização e ecologia de Acinetobacter baumanii degradadora do herbicida Diuron. Rio Claro, 2000. 108 p. Tese (Doutorado) - Universidade Estadual Paulista "Júlio de Mesquita Filho".

14 SCHLÖMANN, M. Evolution of chlorocatechol catabolic pathway. Biodegradation, Dordrecht, v. 5., n. 3-4, p. 301321, 1994.

15 STRAND, S. E. Aerobic biodegradation of polychlorinated biphenyls. Disponível em: <http:// www.cfr.washington.educ./classes.esc.518>. Acesso em: 10 jun. 2003.

16 VASUVEDAN, N.; MAHAVEDAN, A. Utilization of complex phenolic compounds by Acinetobacter sp. Applied Microbiology and Biotechnology, Berlin, v. 7, p. 404-407, 1992.

17 WILLIAMS, P. A.; SAYERS, J. R. The evolution of pathways for aromatic hydrocarbon oxidation in Pseudomonas. Biodegradation, Dordrecht, v. 5, n. 3/4, p. 195-217, 1994 